BULLETIN Bulletin hispanique

HISPANIQUE Université Michel de Montaigne Bordeaux

117-1 | 2015

Les poètes des rhéteurs

\title{
Ana María Matute, Luciérnagas
}

Cátedra, Madrid, 2014

\section{Christian Manso}

\section{CpenEdition}

Journals

Édition électronique

URL : https://journals.openedition.org/bulletinhispanique/3943

DOI : 10.4000 /bulletinhispanique.3943

ISSN : 1775-3821

Éditeur

Presses universitaires de Bordeaux

\section{Édition imprimée}

Date de publication : 1 juin 2015

Pagination : 389-390

ISBN : 979-10-300-0174-7

ISSN : 0007-4640

Référence électronique

Christian Manso, «Ana María Matute, Luciérnagas », Bulletin hispanique [En ligne], 117-1 | 2015, mis en ligne le 01 septembre 2015, consulté le 12 février 2022. URL : http://journals.openedition.org/ bulletinhispanique/3943; DOI : https://doi.org/10.4000/bulletinhispanique.3943

Ce document a été généré automatiquement le 12 février 2022.

Tous droits réservés 


\title{
Ana María Matute, Luciérnagas
}

\author{
Cátedra, Madrid, 2014
}

Christian Manso

\section{RÉFÉRENCE}

Ana María Matute, Luciérnagas, Edición de María Luisa Sotelo Vázquez, Madrid, Cátedra, Letras Hispánicas, n 747, 2014, 397 p. : ISBN 978-84-376-3324-4.

1 Heureuse initiative que celle de Cátedra qui édite ce texte fondateur d'Ana María Matute, lequel eût perdu très certainement en rayonnement et en éclat sans la remarquable Introducción commise au soin de la professeure María Luisa Sotelo Vázquez de la Universitat de Barcelona. Cette étude préliminaire, qui court de la page 11 à la page 97 est des plus éclairante à maints égards. Tout d'abord, quant à la conception de l'écriture, quant à l'art de la fiction chez l'écrivaine barcelonaise qui, née en 1925 en la capitale catalane, se signale très tôt dans le panorama des Lettres espagnoles de la douloureuse après-guerre, en accédant au rang de finaliste du prix Nadal, en 1947, avec son roman Los Abel. Elle est, ensuite, des plus utiles en raison de toute la documentation mise à profit, tant pour ce qui est de la contextualisation attenante à Luciérnagas, que pour ce qui a trait au destin de ce livre qui eut à pâtir des foudres de la censure franquiste. Intitulé initialement Las luciérnagas, ce texte, lui aussi, fut finaliste du prix Nadal en 1949. Cependant le censeur anonyme de l'époque en refusa la publication considérant que «(la obra) resulta destructora de los valores humanos y religiosos esenciales ", tout en soulignant, par ailleurs, qu'elle réunissait d'indéniables qualités littéraires. Remanié au prix d'amendements concessibles, ce livre vit le jour en 1955 sous le titre de En esta tierra, en résonance profonde avec l'axe de narration choisi par l'écrivaine. Enfin, en 1993, après une refonte du texte, destinée à retrouver son substrat primitif, Ana María Matute republie cette œuvre sous un titre qui se démarque considérablement de celui qu'elle avait choisi originellement, Luciérnagas. L'analyse du texte de 1993 qui est alors opérée par María Luisa Sotelo Vázquez pose d'emblée qu'il est à considérer comme un roman de formation, un roman initiatique. Elle se révèle des plus pénétrantes dans son découpage qui présente les 6 premiers chapitres comme La 
partida, à savoir celle de la protagoniste Sol, une adolescente de 16 ans qui, dès le début du conflit fratricide en la capitale catalane, se voit en butte à une série de chocs familiaux, domestiques, de contrariétés dérangeantes, bouleversantes émanant d'une réalité environnante immédiate. À cette partida, qu'il y a lieu de comprendre comme rupture, déchirement, de tout un ordre établi, exhortant à un nouveau départ dans le monde, succèdent 9 chapitres qui sont perçus comme une longue période de iniciación au cours de laquelle Sol va quitter le foyer familial pour se lancer dans un périple urbain pendant lequel, aux prises avec bien des épreuves qu'elle partage avec des ressortissants issus de milieux défavorisés, elle va se forger peu à peu une personnalité, elle va prendre conscience des maux qui foncièrement rongent l'humanité, sans que cela l'amène à une prise de position de nature politique, idéologique, et ce malgré des sympathies nouées avec un milieu anarchisant. Enfin, les 3 derniers chapitres conçus comme $E l$ regreso de Sol à son point de départ, c'est-à-dire son foyer familial, outre qu'ils la dépeignent sous des traits attestant une métamorphose des plus affirmées, voire radicales, tant psychiquement que physiquement, ne peuvent manquer de laisser le lecteur devant des perspectives de clair-obscur, alors que la guerre civile est sur le point de s'achever. Enfin, avant de conclure son Introducción par une bibliographie solide et précieuse, la professeure María Luisa Sotelo Vázquez se penche sur ce qui gouverne la fiction, c'est-à-dire l'épigraphe tirée du Deutéronome: «Verás de frente la tierra que yo daré a los hijos de Israel: Y no entrarás en ella ». À deux reprises, en effet, est particulièrement mise en exergue semblable vaticination: Pablo, l'anarchiste, qui pensait pouvoir faire gagner le pays de Canaan à l'humanité, échoue dans son entreprise et meurt. Cristián, son frère, qui avec Sol semblait former le couple nouveau en mesure de franchir le Jourdain, échoue lui aussi et meurt, Sol portant, cependant, en ses entrailles le fruit de leurs amours. Il y a manifestement chez Ana María Matute un regard sans concession sur cette humanité qui ne cesse de réactiver, réactualiser, le fratricide initial et se condamne de ce fait à ne pas accéder « aux blancs ruisseaux de Chanaan" (comme aurait dit Apollinaire). Ce texte qui apparaît au seuil des années 1950, dont la thématique vaut engagement intransigeant de la part de l'écrivaine en herbe, met en exergue, à l'évidence, une autre génération perdue, à savoir celle des «luciérnagas » qu'évoque Sol dans un monologue intérieur : «Dos animales anónimos, sin méritos ni heroicidad alguna, dos criaturas, ésas que ella vio en el campo al borde de los caminos. Unos, arrastrándose sobre la tierra, otros intentando volar, golpeándose contra las paredes, con la cabeza encendida. Luciérnagas, barcos errantes en la noche » (p. 337). Il est évident que l'oblitération de l'article défini du titre premier est, assurément, à considérer comme une volonté de rehaut du relief d'un substantif auquel il y a lieu d'associer une dimension polysémique plus dense, plus universelle, moins contingente, le temps ayant fait son œuvre, sans qu'une évolution palpable de l'humanité puisse être détectée en cette fin du $\mathrm{XX}^{\mathrm{e}}$ siècle. Ces luciérnagas, tout compte fait, sont des stigmates qui vont perdurant sans ouvrir de véritables perspectives sur une traversée réussie, aboutie, du Jourdain. Cependant il ne saurait échapper au lecteur que Sol (de son prénom Soledad) est loin d'être seule à la fin du texte : Cristián, certes, est mort, qui de près ou de loin participait en tant qu'individu de sexe masculin de cette lutte fratricide déjà inscrite dans l'Ancien Testament. Sol, de par sa nature féminine, échappe en quelque sorte à cette malédiction; elle est susceptible, par conséquent, d'engager l'humanité vers un autre destin, ce qui n'est pas encore vérifiable à l'aube du XXI ${ }^{\mathrm{e}}$ siècle. Ce texte, d'une facture narrative des plus habiles, que traverse un souffle lyrique, rendant compte des 
affres auxquelles ont été exposés les Barcelonais durant les 33 mois de guerre civile, méritait d'être remis en lumière.

\section{AUTEURS}

\section{CHRISTIAN MANSO}

Université de Pau 